\title{
Comparison of the Prevalence of Erectile Dysfunction Between Hypertensive and Normotensive Participants: A Case-Control Study
}

Suresh Kumar ${ }^{1}$, Naresh Kumar Khurana ${ }^{2,3}$, Sameer Lohana ${ }^{4}$, Manoj Kumar Khamuani ${ }^{4}$, Muhammad Khizar Memon ${ }^{4}$, Sidra Memon ${ }^{5}$, Syeda M. Hassan ${ }^{6}$, Hamza Sohail ${ }^{5}$

1. Cardiology, Bolan Medical College, Quetta, PAK 2. Cardiology, Shalamar Medical \& Dental College, Lahore, PAK 3. Cardiology, Shalamar Hospital, Lahore, PAK 4. Internal Medicine, Liaquat University of Medical and Health Sciences, Jamshoro, PAK 5. Internal Medicine, Jinnah Sindh Medical University, Karachi, PAK 6. Medicine, Jinnah Sindh Medical University, Karachi, PAK

Corresponding author: Sidra Memon, sidramemon311@gmail.com

\section{Abstract}

\section{Introduction}

Hypertension is a very common risk factor for erectile dysfunction (ED). In recent time, changes in lifestyle has led to an increase in the prevalence of hypertension, which has increased the risk of ED. The purpose of this study is to assess the prevalence of ED in hypertensive patients and compare various domains of sexual activity between hypertensive and normotensive participants.

\section{Methods}

This case-control study was conducted in an outpatient department of a tertiary health care hospital in Pakistan from March 2019 to September 2019. Two hundred and twelve clinically diagnosed hypertensive patients were enrolled and were identified as case group. Control group consisted of 212 people, without any history of hypertension. Sexual function was assessed with the International Index of Erectile Function (IIEF).

\section{Results}

The prevalence of erectile dysfunction in hypertensive group was $61.79 \%$, compared to $20.28 \%$ in normotensive group. Erectile weakness $(\mathrm{OR}=4.32$, CI 2.64-7.05), impaired morning erection $(\mathrm{OR}=5.02$, CI 2.98-8.47), complete erectile failure $(\mathrm{OR}=2.32$, CI 1.14-4.75), impaired spontaneous erection $(\mathrm{OR}=5.45, \mathrm{CI}$ 3.28-9.03), ejaculatory disturbances ( $O R=5.20$, CI 2.96-9.12) and reduced sexual interest $(\mathrm{OR}=5.12, \mathrm{CI}$ 3.04-8.64) were found to be significantly higher in patients with hypertension compared to normotensive participants.

Review began $11 / 17 / 2020$ Review ended 12/06/2020 Published 12/13/2020

\section{() Copyright 2020}

Kumar et al. This is an open access article distributed under the terms of the Creative Commons Attribution License CC-BY 4.0., which permits unrestricted use, distribution, and reproduction in any medium, provided the original author and source are credited.

\section{Conclusion}

This study has found ED to be prevalent in hypertensive patients. Identifying and acknowledging hypertension as a risk factor may help identify patients with ED and reinforce the clinician's importance of asking sexual history of hypertensive patients.

Categories: Cardiology, Internal Medicine

Keywords: erectile dysfunction, hypertension, sexual dysfunction

\section{Introduction}

Prevalence of erectile dysfunction (ED) ranges from $3 \%$ to $76.5 \%$ in various part of world [1]. ED is defined as the inability to reach or maintain penile erection adequate for sexual intercourse; it has a negative impact on the sexual quality of life of men and their partners [2,3]. Prevalence of ED is expected to rise in the upcoming years due to increase in the life expectancy and aging of the population [4]. Common risk factors for ED include individual's general health status, hypertension (HTN), diabetes mellitus (DM), metabolic syndrome, hyperlipidemia, smoking, and psychiatric/psychological disorders $[2,5]$.

HTN, considered one of the most hazardous cardiovascular risk factors, is a frequent finding in men with ED, with 30\%-50\% of hypertensive; men have erectile dysfunction [5]. Multiple pathogeneses have been identified that link HTN and ED including involvement of Rho/Rho-associated coiled-coil containing protein kinase (Rho/ROCK) pathway, endothelial dysfunction, arteriolosclerosis, and side effects of antihypertensive medications [5]. According to The National Health Survey of Pakistan (NHSP), 18\% of the adults in Pakistan have hypertension, with the incidence increasing to $33 \%$ in people above 45 years of age [6]. High prevalence of hypertension is due to high rate of urbanization where diets high in salts, calories, saturated fats and low in fruits and vegetables are consumed [7]. A study from 2003, compared the prevalence of ED in 


\section{Cureus}

hypertensive men from three countries and found hypertensive men in Pakistan have much higher rate (80.8\%) of ED, compared to Nigeria (57.4\%) and Egypt (63.6\%) [8]. Despite hypertension being very prevalent among Pakistani men, its effect on erectile function is not well studied. In this study, we will calculate the prevalence of ED and other parameters of sexual function in hypertensive men in Pakistan.

\section{Materials And Methods}

This case-control study was conducted in the outpatient department of tertiary healthcare hospital in Pakistan from March 2019 to September 2019. Two hundred and twelve known hypertensive patients were selected through consecutive convenient non-probability sampling and were identified as case group. Control group consisted of two hundred and twelve normotensive people, who visited the outpatient department as patients attendants. inclusion criteria for both case and control group were male above 40 years.

Age, gender, BMI, and smoking status were noted in a self-structured questionnaire. Sexual function was assessed with the International Index of Erectile Function (IIEF) [8]. After taking their informed consent, participants filled the questionnaire with IIEF themselves. A questionnaire in the local language was given and guidance was provided to participants when needed. The responses to IIEF questions were rated on 5point scale. Total possible maximum score was 25 ; higher score indicating better sexual function (Table 1 ).

International Index of Erectile Function (IIEF) Score

22 to 25

17 to 21

12 to 16

1 to 11

\section{Severity of Erectile Dysfunction}

No

Mild

Moderate

Severe

TABLE 1: Sexual function assessed with the International Index of Erectile Function.

Data were analyzed using SPSS for Windows, version 22.0 (IBM Corp., Armonk, NY). Student T-test was performed to test the significance of difference between mean values. Chi-square was performed to test differences in categorical values between two or more groups. P-value of less than 0.05 meant that null hypothesis is not valid.

\section{Results}

In our study, $36.79 \%$ participants in hypertensive men were obese and $24.53 \%$ in normotensive group were obese. The most common age group in both groups was 60 years and older. In this study, the prevalence of ED was found to be $61.79 \%$ in hypertensive group; while in normotensive group, it was $20.28 \%$. Severe ED was found in $24.53 \%$ in hypertensive group, while it was $5.66 \%$ in normotensive group (Table 2). 


\section{Cureus}

\begin{tabular}{|c|c|c|c|}
\hline Variable & Hypertensive men (n=212) & Normotensive men $(n=212)$ & P-value \\
\hline Age, years, mean \pm SD & $55 \pm 12$ & $54 \pm 12$ & NS \\
\hline \multicolumn{4}{|l|}{ Age group } \\
\hline 30-39 years & $12(5.66 \%)$ & $15(7.08 \%)$ & \multirow{4}{*}{ NS } \\
\hline 40-49 years & $53(25.0 \%)$ & $49(23.11 \%)$ & \\
\hline $50-59$ years & $52(24.53 \%)$ & $50(23.58 \%)$ & \\
\hline 60 years and more & $95(44.81 \%)$ & $98(46.23 \%)$ & \\
\hline \multicolumn{4}{|l|}{ Body mass Index } \\
\hline Normal weight $\left(<25 \mathrm{~kg} / \mathrm{m}^{2}\right)$ & 70 (33.02\%) & $100(47.17 \%)$ & \multirow{3}{*}{0.004} \\
\hline Overweight (25-30 kg/m²) & $64(30.19 \%)$ & $60(28.30 \%)$ & \\
\hline Obese $(>30$ kg/m²) & $78(36.79 \%)$ & $52(24.53 \%)$ & \\
\hline \multicolumn{4}{|l|}{ Smoking Status } \\
\hline Never smoker & 101 (47.64\%) & $143(67.45 \%)$ & \multirow{3}{*}{$<0.00001$} \\
\hline Ex-smoker & 34 (16.04\%) & $28(13.21 \%)$ & \\
\hline Current Smoker & $77(36.32 \%)$ & $41(19.34 \%)$ & \\
\hline \multicolumn{4}{|l|}{ Erectile Dysfunction } \\
\hline Yes (<21) & $131(61.79 \%)$ & $43(20.28 \%)$ & \multirow{2}{*}{$<0.00001$} \\
\hline No (22-25) & $81(38.21 \%)$ & $169(79.72 \%)$ & \\
\hline \multicolumn{4}{|l|}{ Severe of Erectile dysfunction } \\
\hline Severe (1-11) & 52 (24.53\%) & $12(5.66 \%)$ & \multirow{4}{*}{$<0.00001$} \\
\hline Moderate (12-16) & $38(17.92 \%)$ & $21(9.91 \%)$ & \\
\hline Mild (17-21) & 41 (19.34\%) & $10(4.72 \%)$ & \\
\hline None (22-25) & $81(38.21 \%)$ & $169(79.92 \%)$ & \\
\hline
\end{tabular}

\section{TABLE 2: Comparison of characteristics between case and control group.}

SD: standard deviation; NS: not significant.

Comparison of prevalence of dysfunction in various domains of sexual activity between both groups as assessed by IIEF shows that prevalence of all sexual dysfunction was higher in hypertensive group compared to normotensive group. Erectile weakness $(\mathrm{OR}=4.32$, CI 2.64-7.05), impaired morning erection $(\mathrm{OR}=5.02$, CI 2.98-8.47), complete erectile failure $(\mathrm{OR}=2.32$, CI 1.14-4.75), impaired spontaneous erection $(\mathrm{OR}=5.45$, CI 3.28-9.03), ejaculatory disturbances $(\mathrm{OR}=5.20$, CI 2.96-9.12) and reduced sexual interest $(\mathrm{OR}=5.12$, CI 3.04-8.64) were significantly higher in patients with hypertension compared to normotensive participants (Table 3). 


\section{Cureus}

\begin{tabular}{|c|c|c|c|c|c|}
\hline Sexual dysfunction domain & Hypertensive men ( $n=212)$ & Normotensive men ( $n=212)$ & Odds Ratio (OR) & $95 \%$ confidence interval & P-value \\
\hline \multicolumn{6}{|l|}{ Erectile Weakness } \\
\hline Present & $82(38.68 \%)$ & $27(12.74 \%)$ & \multirow{2}{*}{4.32} & \multirow{2}{*}{$2.64-7.05$} & \multirow{2}{*}{$<0.0001$} \\
\hline Absent & $130(61.32 \%)$ & 185 (87.26\%) & & & \\
\hline \multicolumn{6}{|l|}{ Impaired morning erection } \\
\hline Present & $78(36.79 \%)$ & $22(10.38 \%)$ & \multirow{2}{*}{5.02} & \multirow{2}{*}{$2.98-8.47$} & \multirow{2}{*}{$<0.0001$} \\
\hline Absent & 134 (63.21\%) & $190(89.62 \%)$ & & & \\
\hline \multicolumn{6}{|l|}{ Complete erectile failure } \\
\hline Present & 26 (12.26\%) & 12 (5.66\%) & \multirow{2}{*}{2.32} & $1.14-4.75$ & $<0.0001$ \\
\hline Absent & $186(87.74 \%)$ & & & & \\
\hline \multicolumn{5}{|l|}{ Impaired spontaneous erection } & \\
\hline Present & $87(41.04 \%)$ & $24(11.32 \%)$ & \multirow{2}{*}{5.45} & \multirow{2}{*}{$3.28-9.03$} & \multirow{2}{*}{$<0.0001$} \\
\hline Absent & $125(58.96 \%)$ & $188(88.68 \%)$ & & & \\
\hline \multicolumn{6}{|l|}{ Ejaculatory disturbances } \\
\hline Present & 69 (32.55\%) & $18(8.49 \%)$ & \multirow{2}{*}{5.20} & \multirow{2}{*}{$2.96-9.12$} & \multirow{2}{*}{$<0.0001$} \\
\hline Absent & $143(67.45 \%)$ & 194 (91.51\%) & & & \\
\hline \multicolumn{6}{|l|}{ Reduced Sexual interest } \\
\hline Present & 79 (37.26\%) & $22(10.38 \%)$ & \multirow{2}{*}{5.12} & \multirow{2}{*}{$3.04-8.64$} & \multirow{2}{*}{$<0.0001$} \\
\hline Absent & $133(62.74 \%)$ & $190(89.62 \%)$ & & & \\
\hline
\end{tabular}

\section{TABLE 3: Comparison of the prevalence of dysfunction in various domains of sexual activity as}

assessed by the International Index of Erectile Function.

\section{Discussion}

Study of ED pathophysiology, its risk factors, and treatment are important to overcome the lack of selfesteem, better relationship with partner and overall health of male patient [9-11]. In this study we analyzed the relationship of hypertension with ED and hypertension and assessed the overall sexual performance of 212 hypertensive Pakistani men, aged 30 and above, using IIEF, by comparing it normotensive participants.

In present study, ED was found in $61.79 \%$ patients with hypertension versus $20.28 \%$ in normotensive ( $p<$ 0.0001). The result is comparable with another study, where Burchardt et al. found out $68.3 \%$ of hypertensive male patients has some degree of ED. Assessing via IIEF, Burchardt et al., observed that hypertensive patients reported high severity of $\mathrm{ED}$ ( $45.2 \%$ in hypertensives versus $10 \%$ in a general population) [12]. We also encountered a similar observation in our study in which $24.53 \%$ hypertensive patients reported severe ED compared to $5.66 \%$ in normotensive group. Giuliano and his colleagues reported the same pattern where they found out that out of $67 \%$ hypertensive patients that reported ED, $80 \%$ patients classified the symptoms as bothersome [13]. The results from all these studies suggest a higher prevalence of ED in hypertensive patient with more severe symptoms reported of ED among hypertensive patients than normotensive population.

Another way to look at it is the prevalence rate of HTN in ED patients. In this regard, Sun et al. reported that $41 \%$ of ED had HTN versus $19 \%$ in age-matched men without ED [14]. Another study examined 272,325 patients with ED and observed that $42 \%$ of the patients had HTN. Moreover, this study also demonstrated that $42 \%$ of these men had hyperlipidemia, $20 \%$ had DM and $11 \%$ had depression. These studies suggest that there may be a causal relationship between CVD and ED [15]. 
The physiology behind erection consists of nitric oxide (NO) production that activates via cGMP pathway resulting in smooth muscle relaxation and dilation of arteries and arterioles, which expands the sinusoids of corpus cavernosa by filling them with blood [16]. The mechanism by which HTN results in ED can be understood is by the fact that long-standing HTN results in endothelial dysfunction. Endothelial dysfunction impairs the ability of arteries and arterioles to dilate properly and weaken the interaction of NO with smooth muscle causing a decrease in relaxation $[17,18]$. Another contributing factor of ED can be the antihypertensive drugs [18]. Several studies have shown that antihypertensive drugs such as thiazide diuretics and beta-blockers are well known in the development of ED. However, other anti-hypertensive therapies such as calcium channel blocker, alpha-blockers, and angiotensin-converting enzyme (ACE) inhibitors report little to no effect on sexual function [18-20]. Current guidelines recommend exploring symptoms of ED before initiating antihypertensive, assessing the symptoms during the treatment, stopping and substituting the offending drug with another antihypertensive when the symptoms of ED manifests, intervening with phosphodiesterase-5 (PDE-5) inhibitors, and avoid concomitant use of nitrates and PDE-5 inhibitors in the patient due to fear of severe hypotension [21].

ED is very prevalent in hypertensive men in Pakistan. It is an important assessment about sexual function that should be made a routine part of management of hypertensive patients. Patients should be counselled about ED as a complication of hypertension and adverse event of various anti-hypertensive medications.

\section{Conclusions}

In our study, we also compared the prevalence of dysfunction in various domains of sexual activity in hypertensive versus normotensive patients. All domains including erectile weakness, impaired morning erection, complete erectile failure, impaired spontaneous erection, ejaculatory disturbances and reduced sexual interest were significantly higher in patients with HTN compared to normotensive participants.

\section{Additional Information \\ Disclosures}

Human subjects: Consent was obtained by all participants in this study. Bolan Medical Complex issued approval Bmc/2018/57. Animal subjects: All authors have confirmed that this study did not involve animal subjects or tissue. Conflicts of interest: In compliance with the ICMJE uniform disclosure form, all authors declare the following: Payment/services info: All authors have declared that no financial support was received from any organization for the submitted work. Financial relationships: All authors have declared that they have no financial relationships at present or within the previous three years with any organizations that might have an interest in the submitted work. Other relationships: All authors have declared that there are no other relationships or activities that could appear to have influenced the submitted work.

\section{References}

1. Kessler A, Sollie S, Challacombe B, et al.: The global prevalence of erectile dysfunction: a review . BJU Int. 2019, 124:587-599. 10.1111/bju.14813

2. Javaroni V, Neves MF: Erectile dysfunction and hypertension: impact on cardiovascular risk and treatment Int J Hypertens. 2012, 2012:627278. 10.1155/2012/627278

3. Fisher WA, Rosen RC, Mollen M, et al.: Improving the sexual quality of life of couples affected by erectile dysfunction: a double-blind, randomized, placebo-controlled trial of vardenafil. J Sex Med. 2005, 2:699-708. 10.1111/j.1743-6109.2005.00119.x

4. Lewis RW, Fugl-Meyer KS, Corona G, et al.: Definitions/epidemiology/risk factors for sexual dysfunction. J Sex Med. 2010, 7:1598-1607. 10.1111/j.1743-6109.2010.01778.x

5. DeLay KJ, Haney N, Hellstrom WJ: Modifying risk factors in the management of erectile dysfunction: a review. World J Mens Health. 2016, 34:89-100. 10.5534/wimh.2016.34.2.89

6. Jafar TH, Levey AS, Jafary FH, et al.: Ethnic subgroup differences in hypertension in Pakistan . J Hypertens. 2003, 21:905-912. 10.1097/00004872-200305000-00014

7. Shah N, Shah N, Shah Q, Shah AJ: The burden and high prevalence of hypertension in Pakistani adolescents: a meta-analysis of the published studies. Arch Public Health. 2018, 76:20. 10.1186/s13690-0180265-5

8. Shaeer KZ, Osegbe DN, Siddiqui SH, et al.: Prevalence of erectile dysfunction and its correlates among men attending primary care clinics in three countries: Pakistan, Egypt, and Nigeria. Int J Impot Res. 2003, 15:S8S14. 10.1038/sj.ijir.3900971

9. Lotti F, Maggi M: Sexual dysfunction and male infertility. Nat Rev Urol. 2018, 15:287-307. 10.1038/nrurol.2018.20

10. Jamil S, Shoaib M, Aziz W, et al.: Does male factor infertility impact on self-esteem and sexual relationship? . Andrologia. 2020, 52:e13460. 10.1111/and.13460

11. Glina S, Sharlip ID, Hellstrom WJ: Modifying risk factors to prevent and treat erectile dysfunction . J Sex Med. 2013, 10:115-119. 10.1111/j.1743-6109.2012.02816.x

12. Burchardt M, Burchardt T, Baer L, et al.: Hypertension is associated with severe erectile dysfunction . J Urol. 2000, 164:1188-1191. 10.1016/S0022-5347(05)67138-8

13. Giuliano FA, Leriche A, Jaudinot EO, et al.: Prevalence of erectile dysfunction among 7689 patients with diabetes or hypertension, or both. Urology. 2004, 64:1196-1201. 10.1016/j.urology.2004.08.059

14. Sun P, Swindle R: Are men with erectile dysfunction more likely to have hypertension than men without 


\section{Cureus}

erectile dysfunction? A naturalistic national cohort study. J Urol. 2005, 174:244-248.

10.1097/01.ju.0000162050.84946.86

15. Seftel AD, Sun P, Swindle R: The prevalence of hypertension, hyperlipidemia, diabetes mellitus and depression in men with erectile dysfunction. J Urol. 2004, 171:2341-2345.

10.1097/01.ju.0000125198.32936.38

16. Ralph DJ: Normal erectile function. Clin Cornerstone. 2005, 7:13-18. 10.1016/s1098-3597(05)80044-4

17. Konukoglu D, Uzun H: Endothelial dysfunction and hypertension. Adv Exp Med Biol. 2017, 956:511-540. $10.1007 / 5584201690$

18. Kloner R: Erectile dysfunction and hypertension. Int J Impot Res. 2007, 19:296-302. 10.1038/sj.ijir.3901527

19. Chrysant SG: Antihypertensive therapy causes erectile dysfunction . Curr Opin Cardiol. 2015, 30:383-390. 10.1097/HCO.0000000000000189

20. Weiss RJ: Effects of antihypertensive agents on sexual function. Am Fam Physician. 1991, 44:2075-2082.

21. Al Khaja KA, Sequeira RP, Alkhaja AK, et al.: Antihypertensive drugs and male sexual dysfunction: a review of adult hypertension guideline recommendations. J Cardiovasc Pharmacol Ther. 2016, 21:233-244.

$10.1177 / 1074248415598321$ 